$$
\begin{array}{r}
\text { Secao de } \\
\text { artilenos } \\
\text { livres }
\end{array}
$$




\section{APONTAMENTOS SOBRE AS FRENTES PIONEIRAS NA ZONA DA MATA RONDONIENSE 《0070-2000)}

Carlos Alexandre Barros Trubiliano

Doutor em História pela Universidade Estadual Paulista (Unesp), Campus de Franca. Docente na Universidade Federal de Rondônia (UNIR). e-mail: carlos.trubiliano@unir.br 
Trubfirano, Carlos Alexandre Barros. Apontamentos sobre as frentes pioneiras na zana da Mata randaniense i $1970-$ 2000). albuquerque - revista de história. val. z, n. 16. jul.-dez./2016, p. 12z-146.

Resumo: Desde o período imperial, existe uma preocupação, por parte do Estado nacional, com a defesa da fronteira oeste brasileira, especialmente após a guerra contra o Paraguai (1864-1870), momento em que se tornam públicas as fragilidades desse território. Diante das vulnerabilidades, já no período republicano, algumas ações - como a expansão de unidades militares, a construção das linhas telegráficas e das ferrovias Madeira-Mamoré e Noroeste do Brasil e, posteriormente, a construção da BR 364 objetivavam a demarcação e efetiva integração dessa região ao território nacional. Um dos efeitos da construção dessas vias de comunicação, ao longo do século $X X$, foi o surgimento de redes de cidades, entre elas a rede urbana da Zona da Mata Rondoniense. Esse ensaio aponta alguns indicativos de desenvolvimento socioeconômico que ajudam a compreender as frentes pioneiras e o processo de formação urbana da rede de cidades da Zona da Mata Rondoniense entre os anos de 1970 a 2000.

Palauras-chave: Ocupação. Cidades. Território. Desenvolvimento.
Abstract: From the imperial period, there is a concern on the part of the national state, the defense of Brazil's western frontier, especially after the war against Paraguay (1864-1870), when they become public the weaknesses that territory. In the face of vulnerabilities, since the Republican period, some actions - such as the expansion of military units, the construction of telegraph lines and the Madeira-Mamore railway and Northwest Brazil and later the construction of the Highway 364 - aimed the demarcation and effective integration this region of the country. One of the effects of the construction of these roads, throughout the twentieth century was the emergence of networks of cities, including urban network Rondoniense Forest Zone. This essay points out some indicators of socioeconomic development that help to understand the process of formation of urban cities network Rondoniense Forest Zone between the years 1970-2000.

Key-words: Occupation, Cities, Territory, Development. 


\section{Considerações iniciais}

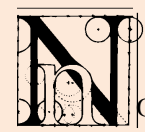

o início do século XX, a rede urbana brasileira, por herança da ocupação econômica dos séculos anteriores, apresentava-se fragmentada, esparsa e nucleada em faixas territoriais próximas à costa litorânea. No interior do país, havia poucas cidades que somavam mais que cinco mil habitantes.

Após a guerra contra o Paraguai, a fronteira oeste tornou-se uma questão de segurança nacional. Medidas foram tomadas para ocupar e demarcar os limites do Brasil. A construção das Linhas Telegráficas Estratégicas, de Mato Grosso ao Amazonas, as Ferrovias Noroeste do Brasil e Madeira-Mamoré, a instalação de quartéis e, posteriormente, a construção de estradas e rodovias representaram não apenas instrumentos de modernização e presença do Estado, mas também impulsionaram a expansão de cidades, constituindo uma rede urbana densa e dinâmica. A rede de cidades assumiu, então, a função estratégica de defesa da fronteira. As cidades da Zona da Mata Rondoniense são frutos da ação desses instrumentos de desenvolvimento, tornando-se partes integrantes e peças importantes na rede urbana da fronteira oeste.

A construção da BR 364 - que chegou a empregar cerca de cinco mil trabalhadores - parte do esforço das políticas de colonização de Rondônia, promovidas pelo Estado durante as décadas de 1970 a 1990 que impulsionaram imigrações e a consolidação da rede de cidades da Zona da Mata. 
A Zona da Mata Rondoniense (ZMR) é formada por uma área de $1.458 \mathrm{~km}^{2}$, que abrange os municípios de Rolim de Moura, Alta Floresta d'Oeste, Alto Alegre dos Parecis, Castanheira, Nova Brasilândia d'Oeste, Novo Horizonte do Oeste, Parecis, Santa Luzia d'Oeste e São Filipe d'Oeste, totalizando uma população de aproximadamente 151.000 habitantes, segundo as estimativas do Instituto Brasileiro de Geografia e Estatísticas (IBGE) de 2014. ${ }^{1}$

Os municípios da ZMR interligam-se através de estradas; a BR-364 é a principal via de escoamento e comunicação. Nessa configuração, a cidade de Rolim de Moura concentra a maior densidade demográfica da região, com 34,74 habitantes por $\mathrm{km}^{2}$, destacando-se como entreposto comercial e, por consequência, como polo socioeconômico. Um reflexo disso é que o setor de serviços constitui a principal fonte de receitas do município. ${ }^{2}$

Rolim de Moura também se destaca por atingir o melhor Índice de Desenvolvimento Humano (IDH) da Zona da Mata - 0,700 segundo o IDHM/IBGE $2010^{3}$ - e o quarto melhor IDH do Estado de Rondônia; contudo, permanece abaixo da média nacional, que é 0,744 .

Além do IDH, outros indicadores, tais como o Produto Interno Bruto (PIB), média de renda per capita, faixa etária, sexo, escolaridade, entre tantos outros, nos permitem construir o perfil sociohistórico da microrregião e pensar nas causas e efeitos sociais do desenvolvimento dos municípios da Zona da Mata.

É importante salientar que a rede urbana zonamatense de Rondônia pode ser considerada como uma das frentes pioneiras mais dinâmicas da Amazônia brasileira, espaço onde se instalaram atividades produtivas - sejam elas de extração, industrial, comercial e de ofertas de serviços, concentrando capital, força de trabalho e poder político.

\footnotetext{
1 INSTITUTO BRASILEIRO DE GEOGRAFIA E ESTATíSTICA. Projeção da população do Brasil e das Unidades da Federação. 2015. Disponível em: <http://www.ibge.gov.br/apps/populacao/projecao/>. Acesso em: 05 de junho de 2016.

2 INSTITUTO BRASILEIRO DE GEOGRAFIA E ESTATísTICA. Projeção da população do Brasil e das Unidades da Federação. 2015. Disponível em: <http://www.ibge.gov.br/apps/populacao/projecao/>. Acesso em: 05 de junho de 2016.

3 INSTITUTO BRASILEIRO DE GEOGRAFIA E ESTATÍ́STICA. Pesquisa Nacional por Amostra de Domicílios (PNAD).Síntese de indicadores 2012.Rio de Janeiro, 2012. Disponível em: <ftp://ftp.ibge.gov.br/Trabalho_e.../2012/.../pnad_brasil_2012.pdf>. Acesso em 05 de junho de 2016.
}

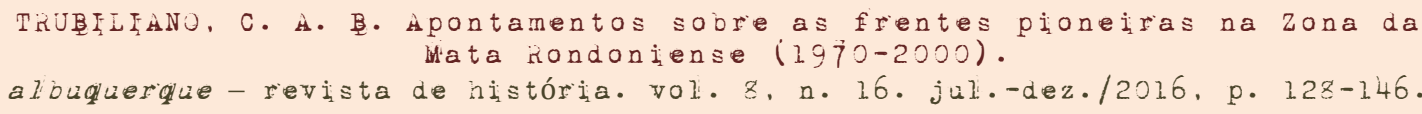


É possível pensarmos a formação da Rede de Cidades na ZMR em dois momentos distintos, que se interligam: Momento I - o processo de formação urbana da rede de cidades da Zona da Mata Rondoniense entre os anos de 1970 e 1990, período marcado por correntes migracionais estimuladas por políticas Estatais; Momento II -as transformações no espaço rural e a consolidação do espaço urbano de 1990 a 2010, temporalidade marcada pelo aprofundamento das relações capitalistas na região.

\section{Momento I - a ZMR entre os anos de 1970 e 1990}

Devemos ressaltar que estudar a formação das cidades, na história contemporânea brasileira, liga-se, em muitos casos, à formação do espaço rural. Deste modo, ao lançarmos um olhar - mesmo que seja de modo preliminar - sobre a "formação urbana da rede de cidades da Zona da Mata Rondoniense", investigaremos as décadas de 1970 a 1990, momento marcado pelo desenvolvimento regional rondoniense; para tanto, faz-se necessário atentar-se ao assentamento populacional no campo, uma vez que a principal característica da formação das cidades, em Rondônia, foi a absorção dos contínuos e intensos fluxos migratórios de trabalhadores rurais "desalojados" das espacialidades de capitalismo mais dinâmico do país, especialmente o Sul e o Sudeste brasileiros, bem como de outras regiões. Tal migração foi incentivada pela colonização pública, por meio da concessão de lotes que variavam entre 50 e 100 hectares, distribuídos por meio de programas de assentamento como os Projetos Integrados de Colonização (PIC's) e o Projeto de Assentamento Rápido (PAR), ambos promovidos pelo Instituto Nacional de Colonização e Reforma Agrária (INCRA). Nos discursos oficiais, tanto durante o regime de exceção quanto na democracia, esses assentamentos populacionais na Zona da Mata, assim comonas demais microrregiões do Estado de Rondônia, foram considerados experiências socialmente "bem-sucedidas" da expansão da fronteira agrícola. Entretanto, de acordo 
com os estudos de Coy ${ }^{4}$, Calvente ${ }^{5}$, Lopes $^{6}$, Cunha ${ }^{7}$ e, mais recentemente, Nóbrega ${ }^{8}$ e Souza ${ }^{9}$, o processo de ocupação sistematizada do território rondoniense foi pautado por uma dinâmica de "diferenciação social no campo", historicamente já observada no "centro" socioeconômico do país (Sul-Sudeste), ao longo dos séculos XIX e XX, cujas características foram o êxodo rural ou "expulsão rural”, a concentração fundiária marcada pelos conflitos de terra e a precarização da força de trabalho do trabalhador rural.

\section{Momento II - a ZMR entre os anos de 1990 e 2010.}

Para compreendermos "as transformações no espaço rural e a consolidação do espaço urbano", partimos da premissa de que, dos anos 1990 até 2010, ocorreu o processo de reorganização do espaço rural, marcado pela crescente formação de latifúndios, o que consequentemente provocou o deslocamento dos trabalhadores do campo ocupantes dos pequenos lotes. Desta feita, os que não conseguiram se empregar nas grandes fazendas foram obrigados a migrar, seja perfazendo o "caminho da volta" para os Estados de origem, ou deslocando-se ainda dentro do território amazônico, especialmente em direção aos Estados do Amazonas e do Pará, em busca da "Canaã" e/ou de novas oportunidades, com a expectativa de se engajar nas vagas oferecidas em grandes empreendimentos ou nos empregos indiretos associados. Vale informar que o governo federal, por meio do Ministério do Planejamento, estima que a região amazônica receberá, até 2020 , a soma de $\mathrm{R} \$ 100$ bilhões em investimentos destinados à construção

\footnotetext{
${ }^{4}$ COY, M. Desenvolvimento regional na periferia amazônica. Organização do espaço, conflitos de interesses e programas de planejamento dentro de uma região de "fronteira": o caso de Rondônia. In: AUBERTIN, C. (Org.). Fronteiras. Brasília: Universidade de Brasília, 1988. p. 167-194.
}

${ }^{5}$ CALVENTE, A. T. Formações não capitalistas no movimento de ocupação da Amazônia: colonização agrícola em Rondônia - 1970/1980. Dissertação (Mestrado em Economia). Instituto de Ciências Humanas da Universidade de Brasília, Brasília, 1980.

${ }^{6}$ LOPES, E. S. A. Colonização agrícola em Rondônia: a relação parceleiro-agregado como manifestação de resistência à expropriação. Dissertação (Mestrado em Desenvolvimento Agrícola). Instituto de Ciências Humanas e Sociais da Universidade Federal Rural do Rio de Janeiro,1983.

7 CUNHA, S. R. P. O xadrez da terra: um estudo da colonização de Rondônia. Dissertação (Mestrado em Ciências Sócio-Ambientais). Núcleo de Altos Estudos Amazônicos da Universidade Federal do Pará, Belém, 1985.

${ }^{8}$ NÓBREGA, Juliana da Silva. A produção da vida como política no cotidiano: A união de terras, trabalho e panelas no "Grupo Coletivo 14 de Agosto", em Rondônia. Tese (Doutorado em Psicologia Social). Universidade de São Paulo, 2013.

${ }^{9}$ SOUZA, M. M. O. Luta, territorialização e resistência camponesa no leste rondoniense (1970-2010). Tese (Doutorado em Geografia). Universidade Federal de Uberlândia, 2011.

TKUBILFANO, C. H. B. Apontamentos sobre as frentes pioneiras na zana da Wata rondoniense (1970-2000).

albuquerque - revista de inistória. val. z, n. 16. jul.-dez./2016, p. 128-146. 
de represas, barragens, estradas e usinas. Contudo, entre os "desalojados" da terra, houve aqueles que se fixaram nas cidades das diversas microrregiões de Rondônia, compondo redes de cidades como a rede urbana da Zona da Mata. Para compreendermos esse processo de consolidação da rede da ZMR, é possível utilizarmos os indicativos de desenvolvimento socioeconômico no intersticio de 1970 a 2000 das cidades que compõem a Zona da Mata.

\section{A consolidação da ZMR}

A expansão urbana da ZMR, consequentemente, gerou aumento na demanda por determinados serviços públicos, tais como saúde, saneamento ambiental, educação e habitação. A princípio, partimos da premissa de que o planejamento sócio-espacial não acompanhou, a contento, o deslocamento populacional - estatalmente estimulados durante as décadas de 1970-90 -, provocando redução na qualidade dos serviços públicos prestados à população. A partir desta percepção, é possível esquadrinhar um panorama - por meio do monitoramento dos indicativos socioeconômicos - da qualidade de vida geral da população, com vistas a dar respaldo às políticas sociais encampadas pelas diversas esferas da administração pública.

Temos por hipótese que as políticas de Estado, a partir da década de 1970 - as quais estimularam a migração para a Zona da Mata Rondoniense -, tiveram como propósito não propriamente fixar o migrante na zona rural, mas formar um contingente populacional que servisse de "mão de obra flutuante", a ser empregada tanto na construção de obras estratégicas na região amazônica como na consolidação das relações capitalistas na "frente econômica" rondoniense. Tal hipótese se assenta na observação da correlação desarmônica entre o "modo de produção familiar" e o "modo de produção capitalista" na disputa por recursos espaciais, em que os interesses dos grupos ligados ao capital prevaleceram nas decisões do Estado, especialmente no que se relaciona ao reordenamento do espaço. Observa-se, ainda, que a precariedade dos serviços públicos limitou a fixação dos "pequenos produtores" na zona rural; desamparados de seus direitos básicos, restou aos mesmos migrarem em busca de melhores condições de vida, seja para as regiões de origem, para as cidades da Zona da Mata ou para outras localidades da região amazônica, motivados pela expectativa de obter colocação nas vagas oferecidas nas grandes obras estratégicas.

TRUBLLFNo, C. A. B. Apantamentas sabre as frentes pioneiras na zana da Mata kondoniense $(1970-2000)$.

albuquerque - revista de história. vol. z, n. 16. jul.-dez./2016, p. 12z-146. 
Com base nos dados estáticos divulgados pelo IBGE, em 2014, os municípios que compõem a Zona da Mata apresentaram média mensal per capita nos domicílios particulares permanentes da área urbana o montante de $\mathrm{R} \$ 400,00$; já os rendimentos mensais per capita da área rural foram de $\mathrm{R} \$ 250,00$. A comparação desses dados com a média do PIB dos municípios analisados sugere que existe uma significativa concentração de renda na região. Vejamos: se considerarmos o montante da população e dividirmos pelo resultado da soma dos PIBs municipais em dados universais, ou seja, sem considerar as diferenças de rendimentos dos residentes das zonas urbana e rural, teríamos, a rigor, uma receita per capita de aproximadamente $\mathrm{R} \$ 1.198,00$ (valor mensal que cada cidadão da Zona da Mata Rondoniense receberia se a riqueza produzida fosse igualmente distribuída). Vale destacar que consideramos aqueles com idade inferior a 14 anos (idade mínima para gerar carteira de trabalho) e os que não possuem qualquer tipo de rendimento; se os desconsiderássemos na redistribuição equitativa do PIB, a receita per capita seria ainda maior, o que reforça a constatação da concentração de renda regional. ${ }^{10}$

Como nos informa Mello e Novais ${ }^{11}$, Prado $^{12}$ e Furtado ${ }^{13}$, o processo de concentração de renda no Brasil é secular, acentuando-se a partir da década de 1960. As políticas de estímulo ao desenvolvimento industrial, implantadas durante a Ditadura Militar (1964-1985), tiveram dois resultados: o primeiro foi o desenvolvimento do parque industrial brasileiro, o que ampliou a força produtiva e, portanto, a capacidade de gerar riqueza cresceu; o segundo foi a distribuição de renda que, nesse período, passou a ter maior concentração. Até a década de $1960,38 \%$ da renda estava concentrada nas mãos de $10 \%$ da população; durante os anos 1980, a concentração chegou aos $51 \%$ da renda. Antes dos anos 1960, a população mais pobre respondia por $17 \%$ da renda nacional; após duas décadas, esse número caiu para $12 \%$. Em outras palavras, o estímulo ao desenvolvimento da capacidade produtiva nacional fez como que quem fosse rico ficasse ainda mais rico; já o pobre ficou ainda mais pobre.

\footnotetext{
10 INSTITUTO BRASILEIRO DE GEOGRAFIA E ESTATísTICA. Pesquisa Nacional por Amostra de Domicílios (PNAD). Síntese de indicadores 2012.Rio de Janeiro, 2012. Disponível em: <ftp://ftp.ibge.gov.br/Trabalho_e.../2012/.../pnad_brasil_2012.pdf>. Acesso em 05 de junho de 2016.

11 MELLO, João Manoel Cardoso de e Novais, Fernando. Capitalismo Tardio e sociabilidade moderna. In: NOVAIS, Fernando (Coord.). História da vida privada no Brasil, v. 4. São Paulo: Companhia das Letras, 1998.
}

12 PRADO JÚNIOR, Caio. Formação do Brasil Contemporâneo. São Paulo: Brasiliense, 1977.

${ }^{13}$ FURTADO, Celso. Formação Econômica do Brasil. São Paulo: Companhia Editora Nacional, 1976. 
Ante a esse cenário, tornasse imprescindível, implantar no Brasil, uma eficaz política tributária redistributiva. Esse problema, em parte, decorre das dificuldades de tributar os rendimentos mais elevados, geralmente não provenientes do trabalho assalariado, tais como as rendas oriundas das aplicações financeiras, de aluguéis (nem sempre declarados) e do trabalho autônomo não registrado. Soma-se, ainda, a questão de natureza política: é notório que, em uma economia na qual a renda se apresenta fortemente concentrada, consequentemente, ocorre a concentração de poder; portanto, a elite política "engessará" medidas que visem à tributação da renda e das riquezas pessoais.

Em Rondônia, uma de suas principais riquezas é a posse da terra. Segundo o INCRA, em seus quarenta anos de atuação na colonização de Rondônia ${ }^{14}$, as terras do Estado foram destinadas em $25 \%$ a pequenos trabalhadores rurais; $6 \%$ à concorrência pública; 34\% áreas de regularização fundiária e 35\% como áreas de aldeamento indígena e unidades de conservação. Entretanto, o próprio INCRA informa que parte significativa das terras destinadas aos agricultores familiares, encontram-se em litígio, como no caso do Projeto de Assentamento Águas Claras, no município de Vilhena, cuja área de aproximadamente 1.200 hectares, com capacidade para atender 72 famílias, encontrasse ocupada irregularmente por latifundiários e agentes públicos. ${ }^{15} \mathrm{Em}$ seu relatório de 2015, a Secretaria Nacional da Comissão Pastoral da Terra (CPT) informou que Rondônia, ao lado do Pará, são os Estados da Federação que registra o maior número de assassinatos por envolvimento em algum tipo de conflito no campo. Ainda segundo a CPT, Rondônia também aparece em primeiro lugar no "ranking" de despejos, em 2015 foram 694 famílias despejadas, no total de 866 casos na Amazônia. ${ }^{16}$ Ante a esses dados, é possível constatarmos que em Rondônia a posse da terra encontra-se em processo de "acumulação primitiva" de capital, cuja as relações nem sempre são reguladas pelo mercado, tendo como principal característica a violência e a superexploração do trabalho.

\footnotetext{
${ }^{14} \mathrm{O}$ INCRA foi órgão responsável pelo surgimento de 50 dos atuais 52 municípios do Estado de Rondônia, através da criação de 175 projetos de assentamentos, que atenderam aproximadamente 63 mil famílias de trabalhadores rurais.

15 Incra 40 anos: Rondônia tem o menor índice de concentração de terras Disponível em: <http://www.incra.gov.br/incra-40-anos-rondonia-tem-o-menor-indice-de-concentracao-de-terras>. Acesso em 05 de junho de 2016.
}

${ }^{16}$ Relatório Conflitos no Campo: CPT Nacional. Goiânia (GO), 2015. Disponível em: <http://www.cptnacional.org.br/index.php/component/jdownloads/send/41-conflitos-no-campo-brasilpublicacao/14019-conflitos-no-campo-brasil-2015?option=com_jdownloads>. Acesso em 05 de junho de 2016. 
Em relação aos motivos da concentração de renda especificamente na Zona da Mata - assim como, em geral, em Rondônia -, sua natureza é histórica, cujas respostas demandam de pesquisas mais aprofundadas.

Ainda no tocante a distribuição da riqueza no Brasil, de acordo com dados do Instituto de Pesquisas Econômicas Aplicadas (IPEA) de 2012 ${ }^{17}$, nas duas últimas décadas, o país tem registrado acentuado crescimento econômico; também é possível afirmar que a pobreza e a extrema pobreza declinaram. Ao longo desse período, a renda per capita dos 10\% mais ricos da população teve um aumento de 16,6\% em termos acumulados, ao passo que a renda dos mais pobres teve notável crescimento de $91,2 \%$. A evolução da renda da população mais pobre deve-se, entre outros fatores, ao histórico de baixos rendimentos dessa camada populacional que, ao receber algum tipo de assistência social, chega a, tecnicamente, dobrar seus rendimentos. Explica-se: segundo a Organização das Nações Unidas (ONU), considera-se pobreza extrema quando as pessoas vivem com menos de US\$ 1 ao dia; a pobreza inclui aqueles que vivem com menos de US\$ 2 por dia. Diante disso, suponhamos que uma família tenha uma renda mensal de R \$250,00 (valor médio na Zona Rural da ZMR) e passe a receber algum tipo de auxílio social, como o Bolsa-Família (2015) - cujo beneficiário recebe, em média, R\$ 167,56. Essa família teria uma evolução de $66,8 \%$ em seus rendimentos. Obviamente, em termos estatísticos e politicamente, o crescimento da renda dos mais pobres chama atenção; contudo, sabemos que, socialmente, o indivíduo que vive com US\$ 2 por dia, parafraseando Guimarães Rosa, é "antes de tudo um forte!". Deve-se considerar, também, que nas duas últimas décadas, a expansão trabalhista e dos programas sociais, como o Benefício de Prestação Continuada (BPC), o Bolsa-Família e o Brasil Sem Miséria, permitiram que a extrema pobreza no país fosse reduzida em $75 \%$, e a pobreza em 65\%, segundo dados do Mapa da Fome da Organização das Nações Unidas para a Alimentação e a Agricultura (FAO) de $2014^{18}$. Entretanto, é preciso informar que, no Brasil, ainda existem mais de 16 milhões de pessoas vivendo na pobreza, ou seja, 8,4\% da população - dados que ilustram a avaliação da Organização das Nações Unidas para

\footnotetext{
17 INSTITUTO DE PESQUISA ECONÔMICA APLICADA. Relatório (2001-2011): desigualdade, pobreza e políticas de renda. In: Texto para discussão n. 155. Brasília: IPEA, 2012. Disponível em: <www.ipea.gov.br/agencia/.../120925_comunicadodoipea155_v5.pdf >. Acesso em 05 de junho de 2016.

${ }^{18}$ Organização das Nações Unidas para Agricultura e Alimentação. Mapa Mundial da Fome em 2014. Brasília: Ministério do Desenvolvimento Social. Disponível em: <http: //www.brasil.gov.br/governo/2014/09/relatorio-indica-que-brasil-saiu-do-mapa-mundial-dafome-em-2014>. Acesso em: 05 de junho de 2016.
} 
a Educação, a Ciência e a Cultura (Unesco) em 2015: o Brasil configura-se, ainda, como um dos países mais desiguais do mundo.

Na contramão do restante do país, a região Norte apresentou retrocesso no que diz respeito ao combate à desigualdade. Relatório de 2012 da Pesquisa Nacional por Amostra de Domicílios (PNAD) mostrou que o índice de Gini da região subiu de 0,488, em 2009, para 0,496, em 2011 (nesse índice, a variação vai de zero, que representa a perfeita igualdade, até um, que significa a desigualdade máxima). Os efeitos nefastos da desigualdade são acompanhados pela retração da distribuição igualitária de rendimentos e pela queda na qualidade da oferta de serviços públicos. ${ }^{19}$

Quanto às precariedades da qualidade de vida da população residente na região Norte, ainda segundo dados do relatório PNAD (2012), uma possível hipótese é o descompasso entre a expansão da oferta de serviços públicos e o crescimento de domicílios - entre 2009 e 2012, a região Norte registrou aumento de 4,2 milhões para 4,4 milhões de residências. Por exemplo, em 2009, a coleta de lixo atendia 79\% da população, aproximadamente 3,34 milhões de domicílios. Em 2012, a coleta passou a atender 3,36 milhões de lares, o equivalente a 75,8\% do total. Ou seja, em termos absolutos, a coleta deixou de atender 3,2\% dos lares. Outro exemplo: em 2009, 2,4 milhões de casas estavam ligadas à rede de água, o que representava 56,7\% dos domicílios; em 2012, a rede de água chegava a 2,48 milhões de casas, representando 55,9\% dos domicílios. Em outras palavras, a proporção de lares beneficiados por serviços básicos como coleta de lixo e rede de água foi reduzida.

É necessário destacar que, entre 2009 e 2012, a região norte aumentou em 63,8\% o número de domicílios ligados à rede coletora de esgotamento sanitário, passando de 547 mil para 896 mil domicílios. Entretanto, em termos absolutos, a rede de esgoto não chega a atender um terço da população. Se pegarmos os dados de Rondônia, a situação é ainda mais problemática: apenas $2,9 \%$ das residências rondonienses estão ligadas à rede de esgoto (a média nacional é $57,1 \%$ ) e somente $62 \%$ tem acesso à água tratada (a média nacional é 85,4\%), o que faz com que Rondônia apresente o menor índice em saneamento básico do país. ${ }^{20}$

${ }^{19}$ Pesquisa Nacional por Amostra de Domicílios (PNAD). Síntese de indicadores 2012. Rio de Janeiro, 2012. Disponível em: <ftp://ftp.ibge.gov.br/Trabalho_e.../2012/.../pnad_brasil_2012.pdf>. Acesso em 05 de junho de 2016.

20 INSTITUTO TRATA BRASIL. Relatório - ranking do saneamento: resultados com base no snis 2012. São Paulo, 22 de Agosto de $2014 . \quad$ Disponível http://www.tratabrasil.org.br/datafiles/estudos/ranking/relatorio-completo-2014.pdf. Acesso em $05 \mathrm{de}$ janeiro de 2016. 
Se estabelecermos que a natureza dos problemas da qualidade de vida da população está ligada à disparidade entre crescimento populacional e oferta de serviços públicos, há que se considerar o histórico migracional de Rondônia. Entre 1980 e 1991, o Estado registrou crescimento populacional de 7,89\% ao ano, enquanto a média nacional, para o mesmo período, foi de 1,93\%. Na década de 1990, houve redução na taxa de crescimento da população rondoniense para 1,68\%, bem próximo à taxa nacional, de 1,36\%. Já na primeira década do século XXI, a taxa de crescimento populacional de Rondônia foi de 1,24\% ao ano, novamente acima da taxa nacional, que foi de 0,9 (segundo a projeção populacional do IBGE em 2015). Como se nota, o crescimento populacional de Rondônia foi superior ao do país em todo período de 1980-2010. Entretanto, é necessário realizar pesquisas, mais aprofundadas, que possam, historicamente, equacionar, em que medida o crescimento populacional influenciou a qualidade da oferta de serviços públicos e as condições de vida da população.

Parece-nos que a debilidade dos serviços está, também, ligada à precarização social na formação da "mão de obra flutuante", empregada na consolidação das relações capitalistas na frente pioneira não apenas rondoniense, mas como em toda Amazônia. Reflexo disso, nos últimos anos, é que o Norte foi a única região brasileira onde a média per capita de anos de estudo não cresceu e se manteve estagnada em 6,6 anos - em contraponto à crescente média nacional, que saltou de 7,0 para 7,3 anos. ${ }^{21}$ Ou seja, para a atual etapa do desenvolvimento capitalista na região, foi necessário um determinado grau de escolaridade da mão de obra, suficiente para consolidar o setor secundário e que atendesse às necessidades da mecanização do trabalho rural. Entretanto, não foram criadas condições educacionais para que os trabalhadores nortistas conseguissem mitigar as escandalosas desigualdades sociais, bem como para que esses agentes sociais tomassem consciência de seu protagonismo para contestar as condições materiais as quais geram a exclusão. ${ }^{22}$ Ou seja, os avanços no sistema educacional na região Norte foram marcados pela dialética da exclusão-includente, cabendo ao Estado fornecer ao cliente - o capital a força de trabalho técnica e socialmente disciplinada. Deste modo, acentuasse a cultura política das desigualdades, que historicamente marca as relações de poder entre as elites e as camadas mais populares do Brasil.

21 Pesquisa Nacional por Amostra de Domicílios (PNAD). Síntese de indicadores 2012. Rio de Janeiro, 2012. Disponível em: <ftp://ftp.ibge.gov.br/Trabalho_e.../2012/.../pnad_brasil_2012.pdf>. Acesso em 05 de junho de 2016

22 GRAMSCI, A. Maquiavel, a política e o Estado moderno. Rio de Janeiro: Civilização Brasileira, 1978. 


\section{ZMR e as suas "Frentes" pioneiras}

Para uma interpretação da ocupação espacial, bem como, formação de rede de cidades da ZMR, é possível utilizaremos as categorias "frente de expansão" e "frente pioneira”, como formade auxiliar nas análises. A partir da década de 1940, geógrafos brasileiros vêm construindo a categoria de "frente pioneira" não apenas como o deslocamento populacional sobre novos territórios, e sim como a criação de novas sociabilidades, fundadas na completude das relações capitalistas, ou seja, a frente pioneira é, também, uma situação espacial e social. Darcy Ribeiro ${ }^{23}$ corrobora a noção de "frente pioneira" por meio da noção de "frente de expansão". Para o antropólogo, a "frente de expansão" é não apenas o deslocamento dos agentes do capital - tais como agricultores empreendedores, comerciantes, instituições políticas e jurídicas -, como também o das populações pobres - como os lavradores, garimpeiros, vaqueiros, castanheiros, seringueiros, agricultores familiares - em direção à fronteira política que também é social e étnica.

Nessa perspectiva, pensamos a noção de "frente pioneira" como o processo de formação urbana da rede de cidades da ZMR, que ocorreu entre os anos de 1970 a 1990; a noção de "frente de expansão" enquadra-se, portanto, na segunda etapa, com vistas à compreensão das transformações no espaço rural e da consolidação do espaço urbano da ZMR entre as décadas de 1990 a 2000. Destarte, o monitoramento dos indicativos de desenvolvimento socioeconômico no interstício de 1970 a 2000 nos possibilitou um panorama dos desdobramentos das "frentes" na ZMR. Vale ressaltar que a distinção periódica das "frentes" possui efeito pedagógico/esquemático, mais do que propriamente analítico, uma vez que as temporalidades da ocupação do espaço, do contato com o "outro", das relações de alteridade levam à intersecção das duas "frentes", que passam a ser compreendidas como "frente econômica", ou o avanço das relações capitalistas.

Como nossa intenção é apontarmos elementos para compreender a implantação e os impactos das políticas de Estado - gestadas a partir da década de 1970 - que estimularam a migração para a ZMR e, posteriormente, a consolidação das relações capitalistas na "frente econômica" rondoniense é preciso ter no horizonte o processe de formação latifundiária no Brasil.

${ }^{23}$ RIBEIRO, Darcy. Os índios e a civilização: a integração das populações indígenas no Brasil moderno. Petrópolis: Vozes. 1977.

TRUBLFino, C. A. B. Apantamentas sabre as frentes pianeiras na zana da Mata rondoniense $(1970-2000)$.

albuquerque - revista de história. val. z, n. 16. jul.-dez./2016, p. 128-146. 
Caio Prado ${ }^{24}$ ao analisar a questão agrária brasileira surge em um cenário de conflitos, desde o processo da colonização europeia, empreendida no século XVI. O autor relacionou a formação latifundiária brasileira ao papel do Brasil no sistema exploratório internacional, no qual teve como função prover o mercado europeu de produtos primário.

Plínio Arruda Sampaio ${ }^{25}$ corrobora com a tese de Caio Prado ao analisar a formação histórica da agricultura brasileira. Para Sampaio é latente a relação de concentração entre o reduzido círculo dos grandes proprietários de terras e a enorme massa da população rural, cuja realidade é marcada: pela miséria, pela produção agrícola em direção contrária à homogeneização da sociedade brasileira e por provocar uma acelerada deterioração dos recursos naturais.

$\mathrm{Na}$ mesma linha de raciocínio, Ariovaldo de Oliveira indica que a inserção cada vez maior do Brasil no agronegócio está ligada ao seu papel no interior da lógica do desenvolvimento do capitalismo globalizado, sendo que “o agronegócio e suas commodities são expressões objetivas desta inserção capitalista das elites brasileiras ao capital mundial" 26 , logo essa expansão capitalista é simultaneamente equalizante e desigual, marcada pela ampliação da divisão social do trabalho.

A expansão das relações capitalistas para Rondônia tem sua história marcada pela produção/extração de matéria-prima. É possível dividirmos esquematicamente o desenvolvimento econômico rondoniense em ciclos.

O ciclo econômico da borracha, ocorreu em dois momentos, o primeiro, por volta de 1877, se insere no final do "boom" da produção da borracha amazônica, momento em que a região Norte foi o maior polo de extração e exportação de látex do mundo, chegando a produzir, em seu auge, 2.673 toneladas de borracha/ano. O segundo momento, teve início em 1942, motivado pelas demandas da indústria bélica da segunda guerra mundial. A produção da borracha promoveu o deslocamento migracional, especialmente de nordestinos, para o vale do Madeira e seus afluentes: rios Machado, Mamoré, Guaporé e Jamari. ${ }^{27}$

24 PRADO JÚNIOR, Caio. História econômica do Brasil. São Paulo: Brasiliense, 1998.

25 SAMPAIO, P. de A. Duas lógicas paralelas na análise da agricultura brasileira. Estudos Avançados, São Paulo, v.11, n.31, p.117-122, 1997.

${ }^{26}$ OLIVEIRA, A. U. Barbárie e modernidade: o agronegócio e as transformações no campo. Goiânia: CPT, 2003. p. 120.

${ }^{27}$ FONSECA, Dante Ribeiro da; TEIXEIRA, Marcos Antonio Domingues. História Regional (Rondônia). Porto Velho. Rondoniana, 2003. 
No início da década de 1950 foram descobertas jazidas de estanho na região de Porto Velho, dando início ao ciclo da extração da cassiterita. Em duas décadas de extração (1970) Rondônia já respondia por 80\% extração do minério de estanho do Brasil. Apontamos inda que na década de 1950, foram descobertos os primeiros garimpos de diamante nas margens do Rio Machado, nas proximidades das cidades de Ji-Paraná e Pimenta Bueno, contudo a produção diamantífera não chegou se configurar como um ciclo econômico. ${ }^{28}$

A partir da década de 1970, Rondônia passou por estímulos que diversificarão sua balança comercial. Tiveram início, simultaneamente, os ciclos da madeira e da criação de gado. Desde a década de 1980, a Amazônia brasileira tornou-se responsável por, aproximadamente, $80 \%$ da produção nacional de madeira. A colonização e o desmatamento da floresta, foram impulsionados pelo governo Federal através de créditos subsidiados e incentivos fiscais, concedidos a indústria madeireira. Entre os anos de 1966 e 1983, a Superintendência do Desenvolvimento da Amazônia (SUDAM) liberou, aproximadamente, US\$ 500 milhões em subsídios diretos para a instalação ou reformulação de 131 projetos madeireiros industriais na Região Amazônica. ${ }^{29}$

Especificamente em Rondônia a instalação da indústria madeireira seguiu a rota da BR-364. A região que compreende os municípios de Pimenta Bueno e Cacoal possuía espécies de maior valor comercial, a saber mogno e cerejeira. Em 1982, haviam nesses municípios, respectivamente, 60 e 96 unidades industriais. Em 1989, o Estado produziu $180.000 \mathrm{~m}^{3}$ de mogno em tora. ${ }^{30}$ A extração madeireira conduziu a ocupação para oeste da rodovia Br-364, promovendo o aparecimento de novos núcleos urbanos, dos quais cabe destacar, regionalmente, a cidade de Rolim de Moura, que serviu de entreposto comercial entre os novos núcleos populacionais e a rodovia.

No decorrer das décadas de 1970-80 as madeireiras se figuraram como a mais importante atividade da indústria pioneira na fronteira oeste rondoniense. Destarte, cidades como Rolim de Moura chegou a ter mais de 100 serrarias em atividade. $\mathrm{O}$ trato com a madeira - assim como de outras matérias primas regionais - era primário, inexistia, nesse período, indústrias de tratamento, ilustrando que a região se encontrava no estágio

\footnotetext{
${ }^{28}$ FONSECA, Dante Ribeiro da; TEIXEIRA, Marcos Antonio Domingues. Op.Cit.

29 ROCHA, Daniela de Paula. Evolução e sustentabilidade do setor industrial madeireiro no Estado de Rondônia. Dissertação (Mestrado), ESALQ/USP, Piracicaba, Brasil. 1999.
}

${ }^{30}$ ROCHA, Daniela de Paula. Op.Cit.

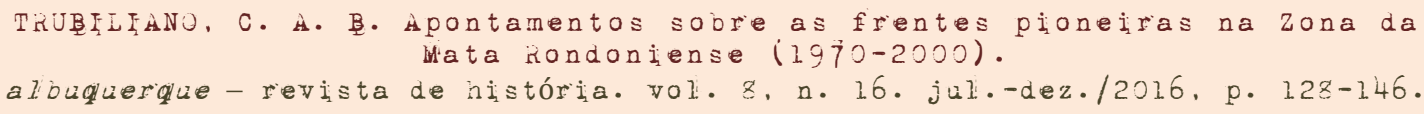


inicial de seu desenvolvimento industrial, e, além disso, revelando o papel periférico de Rondônia em relação aos outros "centros" econômicos do Brasil. ${ }^{31}$

Em consonância as derrubadas das matas, estavam os projetos políticos para colonização de Rondônia. Durante as décadas de 1970-80 a colonização pública feita pelo Incra, baseada na distribuição de lotes de 50 a 100 hectares, constituiu como canalizador dos fluxos migracionais de camponeses "expulsos" das frentes pioneiras "consolidadas" (Paraná, Mato Grosso do Sul, Mato Grosso, etc.). ${ }^{32}$

A escolha de Rondônia como zona de colonização devesse, entre outros fatores, por ser zona de fronteira internacional; por sua localização na continuidade direcional do movimento das frentes pioneiras - que tem início na década de 1940 com a Marcha para Oeste - que se deslocaram das regiões Sul (Paraná) e Centro-Oeste (Mato Grosso do Sul, Mato Grosso) em direção ao Norte; a situação jurídica das terras em Rondônia, marcada pela existência de grandes áreas de terras públicas, o que facilitou a colonização oficial; a existência de terras férteis, acima da média da região amazônica. O sistema de colonização começava pela construção rudimentar de estradas de penetração e suas vicinais, conhecida como "espinha de peixe", pela delimitação dos lotes cobertos por floresta virgem e posteriormente pela derrubada da mata. As técnicas agrícolas empregadas eram rudimentares com o plantio direto após a queimada; as culturas de subsistência como arroz, mandioca, milho e feijão, em alguns lotes, foram completadas por culturas de mercado - incentivadas por instituições governamentais - como no caso do cacau e da borracha, ou trazidas pelos colonos como no caso do café. ${ }^{33}$

Durante a década de 1970 o crescimento demográfico de Rondônia apresentou a taxa mais elevada do Brasil, com média/anual de 15\%. Na década de 1980, mais de 50\% da população residente no Estado vivia há menos de 10 anos na região. ${ }^{34}$ Mesmo diante do notório crescimento populacional, os projetos colonizatórios não tiveram o efeito preconizado pela propaganda do governo militar de "terra sem homens para homens sem

\footnotetext{
31 COY, M. Desenvolvimento regional na periferia amazônica. Organização do espaço, conflitos de interesses e programas de planejamento dentro de uma região de "fronteira": o caso de Rondônia. In: AUBERTIN, C. (Org.). Fronteiras. Brasília: Universidade de Brasília, 1988.
}

${ }^{32}$ COY, M. Desenvolvimento regional na periferia amazônica... Op. Cit; BROWDER, J.O. Madeireiros na Mata Pluvial-Tropical... Op.Cit; HALL, Anthony. Developing Amazonia: Deforestation and social conflict in Brazil's Carajas Programme. Manchester University Press, Manchester, UK. 1989.

33 COY, M. Desenvolvimento regional na periferia amazônica... Op. Cit

${ }^{34}$ COY, M. Desenvolvimento regional na periferia amazônica... Op. Cit 
terra", uma vez que, sem infraestrutura a fixação dos "homens" à terra se revelou impossível.

No que tange o projeto político do Governo Militar para a colonização regional rondoniense, uma hipótese - a ser melhor fundamentada em futuras pesquisas ${ }^{35}$ - é a associação entre os programas de assentamento populacional de caráter eminentemente provisório e a expansão da indústria madeireira, permeado pela lógica de que, na medida em que se derrubava a floresta formava-se o pasto. Devemos informar que a transformação da floresta em pastagem não é exclusividade de Rondônia. Segundo dados do Instituto Nacional de Pesquisas Espaciais até 2011, dois terços da área de floresta amazônica aberta haviam se transformado em pastagens. ${ }^{36}$

A colonização da Amazônia "pelas patas do boi" foi, a priori, projeto do governo militar. ${ }^{37}$ Entre 1966 e 1967, o governo Federal colocou em curso a "Operação Amazônia", que consistiu em ações governamentais e leis como principal objetivo de expandir a pecuária. Para os militares a pecuarização cumpriria duplo papel: economicamente atenderia a crescente demanda internacional por leite e proteína bovina; geopoliticamente, promoveria a ocupação de "espaços vazios" no Norte do Brasil, ao mesmo tempo interligaria a região ao restante do país. No bojo da "Operação Amazônia”, o Plano de Desenvolvimento Nacional (1º PND 1972-1974) criou instrumentos fiscais para incentivar a agropecuária na região. O PND concedia total isenção de impostos às empresas que investissem na Amazônia, os investidores também receberam isenções de taxas tanto para importação como para exportação, crédito subsidiado pela SUDAM e acesso a fundos especiais de investidores. Segundo Anthony $\mathrm{Hall}^{38}$, os principais beneficiários do PND foram os empresários ligados a criação de gado, uma vez que apresentavam o perfil para captar os recursos destinados pelos programas.

\footnotetext{
${ }^{35}$ Informo que esta questão é tema norteador da pesquisa: “Formação da Rede de Cidades na Zona da Mata Rondoniense (1970-2000)", sob a coordenação do Dr. Carlos Alexandre Barros Trubiliano, vinculada junto ao Departamento de História, do Campus de Rolim de Moura da Universidade Federal de Rondônia.

36 INPE \& EMBRAPA: Instituto Nacional de Pesquisas Espaciais e Empresa Brasileira de Pesquisa Agropecuária. Levantamento de informações de uso e cobertura da terra na Amazônia, 2011. Disponível em: <http://www.inpe.br/cra/projetos_pesquisas/terraclass. php>. Acesso em 05 de junho de 2016.

37 BROWDER, J.O. Madeireiros na Mata Pluvial-Tropical... Op. Cit; HALL, Anthony. Developing Amazonia: Deforestationand social conflict in Brazil's... Op. Cit
}

${ }^{38}$ HALL, Anthony. Developing Amazonia: Deforestationand social conflict in Brazil's... Op. Cit 
Nos anos do "milagre econômico" brasileiro (1968-1973), a exploração econômica para região Norte, foi marcada pela quase ilimitada distribuição territorial da periferia amazônica, com vistas a desenvolver as atividades de business privado. $\mathrm{Na}$ execução dosPND I (1972-1974) e PND II (1975-79) foi criado o programa Poloamazônia, com o objetivo de desenvolver a infraestrutura econômica regional. $\mathrm{O}$ programa baseou-se no conceito de polos regionais de crescimento, separados de maneira setorial como, por exemplo, Polo de Extração de recursos minerais de Carajás ou áreaspolo de criação de gado com possível processo industrial. Ao todo foram criados 15 pólos de crescimento para atrair a iniciativa privada.

Diante dos incentivos fiscais e tributários, investidores de capital nacional e internacional foram atraídos para expandirem seus negócios para a Amazônia. Desta feita, contando com fartos subsídios oficiais, grupos de investimento, bancos, companhias de seguro, empresas privadas e estatais, mineradoras, cias de transportes e/ou de construção de estradas passaram a investir na devastação da floresta, com vistas, a introdução de grandes projetos de criação extensiva de gado. ${ }^{39}$

Por possuírem know-how na exploração das terras, foram subcontratados fazendeiros de gado de outros estados brasileiros. Oficialmente, a Federação destinava para implantação das fazendas a área máxima de 60 mil hectares, contudo, foram cridas propriedades com 140 mil hectares, como a fazenda "Santana do Araguaia", no Sul do Pará, administrada pela Companhia Vale do Cristalino, uma subsidiária da Volkswagen do Brasil. Para que se tenha uma ideia da dimensão espacial da fazenda, essa área corresponde ao tamanho da cidade de São Paulo, ou sete Wolfsburg, município no norte da Alemanha que abriga a sede da Volkswagen. ${ }^{40}$

Esses empreendimentos em poucos anos, foram responsáveis pela destruição de consideráveis extensões de floresta tropical no Norte de Mato Grosso, Centro-Sul de Rondônia, Sudeste e Leste do Pará.Se forcarmos somente em Rondônia, nos cinco primeiros anos (1973-78) da implantação dos projetos de colonização, foram desmatados $4.200 \mathrm{~km}^{2} \mathrm{o}$ que corresponde a $1,7 \%$ do território total do estado. Dez anos depois, em 1988, o desmatamento atingiu $12,57 \%$ da área total do estado. ${ }^{41}$

39 KOHLHEPP, Gerd. Conflitos de interesse no ordenamento territorial da Amazônia brasileira. Estud. av. São Paulo , v. 16, n. 45, 2002

40 KOHLHEPP, Gerd. Conflitos de interesse no ordenamento territorial da Amazônia... Op. Cit.

${ }^{41}$ BRASIL, Instituto Brasileiro do Meio Ambiente - RELATÓRIO DO MONITORAMENTO DO DESMATAMENTO $\begin{array}{lllll}\text { NOS BIOMAS BRASILEIROS POR SATÉLITE } & \text { (IBAMA/CSR). Disponível }\end{array}$ 
Os territórios mais afetados localizam-se nas confluências dos municípios de Ariquemes, Pimenta Bueno, Cacoal e Ji-Paraná onde o desmatamento atinge percentuais acima $50 \%$ da área total do município. Rolim de Moura, centro da ZMR, registrou no final da década de 1980 a marca de $74,5 \%$ de desmatamento da extensão total do município. ${ }^{42}$

Em meados da década de 1980, na Amazônia, como todo, os projetos oficiais de fazendas de criação de gado, foram responsáveis, diretamente, pelo desmatamento de cerca de 140 mil $\mathrm{km}^{2}$. Somadas essas as propriedades ocuparam, aproximadamente, nove (9) milhões de hectares. ${ }^{43}$

Como efeito econômico a Amazônia Legal abriga hoje (2016), por volta de, 40\% do rebanho bovino nacional, enquanto em 1977 correspondia a soma de 8\%. No que tange aos efeitos socioambientais, estas políticas de Estado causaram severos danos aos biomas da região, como erosão, esgotamento de nutrientes do solo, encrostamento da superfície do solo e distúrbios climáticos e aquíferos. Destaca-se também, os danos causados pela especulação imobiliária de terra, marcadopor violentos conflitos envolvendo populações indígenas, fazendeiros e posseiros de toda sorte.

\section{Considerações finais}

Neste ensaio a ZMR serviu como microcosmo para refletir sobre o histórico da recente ocupação do espaço amazônico em geral e, especificamente, de Rondônia. O avanço das frentes pioneiras para áreas fronteiriças, está ligado ao processo de capitalização do campo nas zonas pioneiras do Centro-Sul do Brasil. A partir da segunda metade do século XX, a ideia da região amazônica, representada como espaço de potencialidades, passa a ser revigorada. Nesse contexto, o Estado assumiu a iniciativa de ordenar a modernização e a ocupação da região Norte através de projetos geopolíticos.

Para Rondônia foram tangidos colonos pobres em busca de terra e empresas capitalistas em busca de lucros. A ocupação do espaço teve como tônica a degradação do homem e do meio natural. A colonização agrícola foi um desdobramento da expansão civilizacional do capital marcada por conflitos, cujas feridas não cicatrizaram.

em:<http://www.mma.gov.br/estruturas/sbf_chm_rbbio/_arquivos/relatoriofinal_cerrado_2010_final_7 2_1.pdf>. Acesso em 29 de julho de 2016

42 Atlas Geoambiental de Rondônia. Porto Velho: SEDAM, 2002.

${ }^{43}$ KOHLHEPP, Gerd. Conflitos de interesse no ordenamento territorial da Amazônia... Op. Cit. 